\title{
DOBLE EJEMPLARIDAD DE LA MUJER EN DISCURSOS RELIGIOSOS NOVOHISPANOS DEL SIGLO XVII ${ }^{1}$
}

\author{
MANuel PÉRez \\ Universidad Autónoma de San Luis Potosí - México \\ ramon.perez@uaslp.mx
}

\begin{abstract}
T a representación de la mujer en discursos religiosos cristianos es asunto bien estudiado. Su lugar central y fatal en la tragedia humana, su responsabilidad en la expulsión del paraíso, su debilidad moral e intelectual constitutiva y su permanente condición de puerta abierta al pecado, así como la consecuente necesidad de su control para la buena marcha de la sociedad, son temas ya comunes en los estudios sobre pensamiento eclesiástico ${ }^{2}$. Más aun, gracias al estudio de esas representaciones sabemos que en Occidente la mujer fue considerada, hasta hace realmente poco, un mal necesario, un ser inferior, tramposo y funesto, incapaz de alcanzar la grandeza a la que sí estaban llamados los hombres ${ }^{3}$.
\end{abstract}

$1 \quad$ Este artículo se ha desarrollado dentro del proyecto «La mujer frente a la Inquisición española y novohispana» (FEM2016-78192-P), I+D de Excelencia del Ministerio de Economía y Competitividad (MINECO), financiado por la Agencia Estatal de Investigación (AEI) y el Fondo Europeo de Desarrollo Regional (FEDER, UE); y del grupo de investigación «Mentalidades mágicas y discursos antisupersticiosos (siglos XVI, XVII y XVIII)», grupo consolidado por la Universidad Autónoma de Madrid.

2 Para el caso hispano, véase Cátedra (1986) para la España medieval; y Martí (2004) para la España del siglo xvi; Cangas (2006), Baena (2011) y Castillo (2014) para la Nueva España; así como López (2005) para el virreinato del Perú, entre otros.

3 El estudio de las representaciones tiene la virtud de conducirnos a descripciones o valoraciones generales que pueden precisar la información que poseemos sobre los hechos concretos, pues la suma de valoraciones de lo femenino termina por coincidir con el lugar que la sociedad ha ofrecido históricamente a las mujeres (Chartier 1992).

Edad de Oro, XXXVIII (2019), pp. 217-233, ISSN: 0212-0429 - ISSNe: 2605-3314

DOI http://doi.org/10.15366/edadoro2019.38.011 
Las fuentes de estas representaciones, como cabría esperar, se encuentran en la Biblia y en los textos patrísticos (Ortega 1987; Bavel 1994); fray Luis de León, por ejemplo, se apoya en los Proverbios para construir la imagen y función ideales de la mujer en La perfecta casada (León 1972: 44). Prácticamente todos los padres de la Iglesia consideraron la sexualidad femenina (y aun la sexualidad a secas) como un problema de salvación: Justino Mártir (100-165 d. C.) defendía la castidad como condición indispensable para alcanzar el cielo, Clemente (siglo I) consideraba que el único fin de la mujer en el matrimonio era la procreación, mientras que Orígenes (185-254 d. C.) llegó a considerar un mal menor el incesto, si aseguraba la reproducción (a apropósito de Lot, que cohabitó con sus hijas) (Ranke 1994: 53). Para los siglos XVI y XVII, el mundo hispánico se encontraba en perfecta utilización y refuncionalización plena de aquellos antiguos tópicos del discurso religioso sobre las mujeres. Estela Castillo se hace eco, por ejemplo, de un poema anónimo novohispano del siglo XVII recogido por el Santo Oficio y titulado, curiosamente, «Sermón», que incluye «la caída» de la mujer, su pecado y su «traición» a la humanidad: «Que una mujer, Job dijo, es suficiente / De hacer apostatar a el mas sapiente. / Todo un reyno destruye una mujer» (apud Castillo 2014: 54-55).

Uno de los lugares del discurso religioso donde es posible observar con mayor claridad la dimensión ideológica y retórica de las representaciones es la argumentatio, que consiste, como se sabe, en el sustento o defensa de la causa del discurso con base en pruebas, inductivas o deductivas. Las pruebas inductivas, conocidas en Grecia como paradigmata y en Roma como exempla, son documentos preciosos para el estudio de las representaciones debido a su abundancia en los discursos de estilo humilde, su poder persuasivo y mnemotécnico. Los exempla son textos muy útiles para la determinación de contenidos ideológicos o políticamente intencionales del discurso, pues en tanto pruebas se vinculan poderosamente a la causa que se defiende, no solo reafirmando la enseñanza sino también dotándola de contexto, ubicación y pertinencia en la lógica del propio discurso y en la lógica del sistema ideológico en su conjunto.

Desde el año 2005 he venido recogiendo una muestra de exempla novohispanos (Pérez 2008, 2011, 2012 y 2017), hasta constituir una colección anotada de relatos probatorios con base en un criterio taxonómico (Pérez 2018) que recupera los genera causarum de la Antigüedad: deliberativo, panegírico y judicial, asumiendo que aquellos tres géneros del discurso clásico pervivirían, si bien refuncionalizados, todavía en el siglo XVII (Pérez 2017). Consideré discursos deliberativos las pláticas jesuíticas, porque desarrollaban una noción de virtud cristiana de profundo cariz político, como era la concepción religiosa del cristianismo que compartían los miembros de la Compañía de Jesús (Pérez 2008 y 2011). Como discurso panegírico he trabajado algunas crónicas religiosas, pues en ellas el relato propiamente historiográfico se subordina al propósito del encomio de la Orden 
y sus miembros ${ }^{4}$. Finalmente, he considerado discursos judiciales los sermones o pláticas que suelen contener los tratados de extirpación de idolatrías o brujerías, pues no parecen esconder demasiado su carácter punitivo ni su propósito de persuadir acerca de una culpa y unos culpables, de ofrecer a los curas doctrineros elementos para descubrir y perseguir la heterodoxia indígena hasta extirparla.

En los tratados de idolatrías es perfectamente previsible una representación femenina adversa, alimentada de los más primitivos prejuicios misóginos, como en el Tratado de hechicería y sortilegios de fray Andrés de Olmos, donde se expone la debilidad satánica esencial de la mujer en los siguientes términos: «el Diablo engaña muy fácilmente a las mujeres: es así porque la primera fue engañada nuestra primera madre, porque no fue el varón que él engañó primero, y porque él sedujo fácilmente a la mujer con falsas palabras» (Olmos 1990: 47); es decir, por la mujer habría entrado el pecado al mundo y en el mundo se mantenía gracias a que ellas, debido a su temperamento pasional,

se dejan mucho dominar por la ira y el enojo, fácilmente se encolerizan, son celosas, envidiosas; haciendo sufrir, imponiendo tormentos a otros quieren aplacar su corazón y anhelan con facilidad que les pasen a las gentes cosas tristes y penosas. Pero, como pocas perseveran, son bastante fuertes, para saciar su corazón con la muerte de alguien, no les es posible matar a quien aborrecen o atormentan. Por eso se dice que siguen al Diablo para que las ayude a hacer aquello que desean, las maldades que ansía su corazón (Olmos 1990: 48-49).

Por supuesto que, aun cuando la afirmación anterior concierne a las mujeres en general, fray Andrés de Olmos está refiriéndose a las brujas, aunque pareciera que entiende la brujería como una evolución esperable de la condición perniciosa natural de la mujer. En cualquier caso, vicios pasionales y egocéntricos sí que son adjudicados a la condición femenina con frecuencia por esos años, y no solo en los tratados de idolatrías; por ejemplo, sobre esta pecaminosidad y maldad proverbial de las mujeres, en una plática predicada el 18 de enero de 1691 dedicada a vituperar la práctica de la adivinación con base en agüeros y sueños, el jesuita Juan Martínez de la Parra cuenta que

Caminaba por la Italia un soldado, y embargándole los pasos una grave enfermedad lo obligó a detenerse por curarse en un mesón. Llevaba una bolsa llena de reales, y temeroso de que se la hurtaran, entretanto que sanaba, diósela a guardar a la huéspeda. Fue corriendo los términos su achaque, y la mesonera, ya con enfermedad de

4 En particular, la de la provincia carmelitana de san Alberto de México titulada Tesoro escondido en el monte Carmelo mexicano [...], escrita entre 1635 y 1646 por fray Agustín de la Madre de Dios. Un estudio sobre la dimensión ejemplar y retórica de esta obra puede verse en Pérez (2012). 
bolsa, fue empeorando del achaque de la codicia; y tanto, que hallándose ya mejor el soldado para proseguir su viaje le pidió su bolsa, ella lo consultó con su marido y determinaron de negar (Parra 1701: 125) ${ }^{5}$.

Ante la negación de la existencia de la bolsa de dinero por parte de la mesonera, el soldado montó en cólera y sacó la espada, los mesoneros llamaron a la justicia y el soldado fue apresado; como nadie podía probar la existencia de aquella bolsa (excepto el diablo, que conocía su ubicación tanto como el corazón de aquella mujer perversa), al soldado ya lo estaban por condenar a muerte. Sin embargo, antes de ser llevado a juicio, el diablo se presenta ante el soldado para ofrecerle un trato; él lo defendería en el tribunal con el fin de descubrir el pecado de los mesoneros y llevárselos al infierno: «cuando te saquen a tribunal, di que tú como soldado no entiendes de esas defensas, que te permitan por abogado al que tú nombrares, que yo estaré allí». Y efectivamente, «el demonio abogó como un demonio, con tal copia de razones, autoridades y argumentos que a todos los tenía pasmados y atónitos»; al final el diablo revela la ubicación de la bolsa y logra que la mesonera se condene al jurar repetida y desesperadamente « ¡ el diablo me lleve si yo sé de tal bolsa!», lo gritó tantas veces que el diablo procedió en consecuencia (Faya 1632: 297r-298r — aunque ubica los sucesos en Alemania, no en Italia-; Río 1608: I, III, 7) ${ }^{6}$. Así, al igual que en el pasaje del Génesis que narra el pecado original y que ubica a la mujer como primera interlocutora de la serpiente, acá la mesonera es también puerta de la tentación y del pecado; además, parece quedar claro que la mujer es aquí más perversa que el propio diablo, quien se limita a cumplir con su deber e incluso salva de la muerte a un inocente.

Por supuesto, el mayor pecado al que abría puertas la mujer no era la avaricia, sino la lujuria; aunque, al final, todos resultaban desórdenes del apetito que una constitución débil y moralmente defectuosa como la femenina era incapaz de resistir, siendo así el punto flaco de la debida resistencia humana al príncipe del mundo. De todos modos, parece que el discurso religioso gustaba de asociar los desórdenes del sexo con los del dinero, pues los ejemplos al respecto abundan, como el siguiente del carmelita fray Agustín de la Madre de Dios, que narra cómo dos jóvenes

$5 \quad$ Luz de verdades catholicas y explicacion de la doctrina christiana [...], de Juan Martínez de la Parra, es una colección de pláticas doctrinales que sería publicada en tres tomos entre $1691 \mathrm{y}$ 1696, alcanzando gran fama en su época, no solo en México. Aquí cito, modernizada, la edición de 1701 impresa en Barcelona por Juan Jolis.

6 Como evidencia de que estos textos y representaciones no han desaparecido del todo, me permito anotar en este y los demás exempla citados su pervivencia como motivos en índices de la tradición oral: «821A Thief Rescued by the Devil. An innocent man (in league with the devil, who once was kind to the devil) is accused of theft. The complainant swears by the devil [C12.2] that the mains guilty. The devil helps the accused by carrying the complainant (judge) out of the court room [G303.22.11] (and thus repays the hospitality of the accused man [Q45.2])» Uther (2011). 
españoles que hicieron buena fortuna en la Nueva España, ya no la tuvieron tanto cuando «rindieron sus corazones a dos mujeres a quienes llamaban amigas, y eran las enemigas de sus almas; que las mujeres malas eso son [...] si los hombres conociesen con verdad lo que es la mala mujer, que ninguno halagaría en su pecho víbora venenosa que le despedazase las entrañas ni abrigaría en su corazón al fuego más furioso» (Madre de Dios 1986: II, XVII, 6.). El caso fue que estas «amigas» no hicieron otra cosa que explotar a los jóvenes y acabar con sus haciendas, usando su cuerpo como mecanismo de control; de modo que cuando los mancebos, viendo cómo perdían todo, determinaron alejarse de estas mujeres perniciosas, ellas los asesinaron con veneno, concluyendo así en el plano material lo que ya de sí constituían en el espiritual: el emponzoñamiento del alma de los dos incautos?

La mujer ilustra así un par de vicios terribles y, por ende, su representación narrativa constituye un ejemplo contrario de las virtudes que se intentaban persuadir: la castidad y la generosidad. Esta representación de vicio debía implicar su castigo, y ello constituía retóricamente no solo una promesa o amenaza sino, sobre todo, su realización simbólica por medios patéticos, mediante la exposición detallada de horrorosos tormentos post mortem, instituyendo con ello una didáctica del terror de largo aliento. Se trata de una manipulación del pathos usada con frecuencia por predicadores de la época, como Martínez de la Parra cuando cuenta la infernal justicia aplicada sobre una «señora bailadora» que escandalizaba a toda la villa de «Bravancia», aun en domingos y fiestas de guardar, con sus «juntas y academias en su casa de mozuelos casquilucios y de mujercillas bailadoras, trúhanes y coplistas». Una tarde, mientras ella bailaba con sus amigos, quiso salir al balcón a ver el juego de pelota que algunos muchachos hacían en la calle, pero, para su desgracia, la pelota «gobernada de soberano impulso se coló por el balcón, y dándole a la señora dama santificadora de tales fiestas en la frente, la estrelló en la pared los sesos rotos, y en menudos pedazos los cascos». El castigo no quedó ahí, pues mientras la mujer era velada en el mismo lugar donde antes se bailaba «rompiendo por la gente y llenando de horrores y bramidos el aire, un feísimo negro toro echando fuego y humo por los ojos y narices, corriendo hacia las andas, a testeradas, a manotadas, a bocados destrozando en menudas piezas el cuerpo, lo hizo el demonio que bailara al son de sus bramidos. Y dejándolo así se

7 Un dato curioso es que las mujeres administraron tal veneno en sendas tazas de chocolate («bebida ocasionada a cualquier mal», dice el carmelita), desde que el chocolate había causado más de un conflicto en esos años: se discutía incluso si su consumo rompía o no el ayuno (asunto dictaminado reiteradamente por varios papas: Gregorio XIII, Clemente VII, Pablo V, Pío V, Urbano VII, Clemente XI o Benedicto XIV) y, sobre todo, se discutían sus probables efectos afrodisiacos; aunque, a decir de María Águeda Méndez, siguiendo a Sophie D. Coe y Michael Coe, ello obedecía más a una obsesión española con el sexo que a la realidad de su uso entre los indígenas y el pueblo llano (Méndez 2001: 81-96; Coe 1996: 94-95). 
desapareció» (Parra 1701: 173-174) desmembramiento posterior del cuerpo, con profusión de detalles, logra un efecto terrorífico similar al que buscarían posteriormente los cuentos góticos, a decir de Booth, para quien «For Poe's special kind of morbid horror, a psychological detail, has conveyed by an emotionally charged adjective, is more effective than mere sensual description in any form» (Booth 1983: 203).

Y así como la avaricia y la lujuria, también la vanidad como típico vicio femenino se encuentra asentada en estos textos; un vicio con un sesgo satánico mucho más intelectual que los dos anteriores, dicho sea de paso. Y es que para el pensamiento religioso de la época, la vanidad femenina emparentaba directamente con la soberbia de Satán por lo que era blanco de los más duros vituperios por parte de los predicadores, dice el jesuita: «no puedo negar que muchas se adornarán como la paloma, que opuesta al sol brillan sus plumas, pero paloma. Mas ¿cuántas se pintan y se recaman como la serpiente, que mientras más pinta con más bellos matices peor es, y más mortal su veneno», a lo que sigue un relato alegórico en el que dos dragones asolaban el camino al cielo, tendiendo una red y llevando las almas atrapadas al infierno; se trata de una alegoría explicada, en la que los dragones son «las galas profanas, torpes y provocativas de las mujeres» (Parra 1701: 290). Lo mismo Francisco de Florencia, en su Historia de la provincia de la compañía de Jesús de Nueva España, se pronuncia contra las «galas» femeninas, que fomentan la sensualidad, la ambición, la vanidad, la soberbia y el escándalo, «porque quien cuida mucho de aplacer a los ojos humanos, muy poco cuida de agradar a los ojos divinos: que no anda muy ataviada de virtudes en el alma, quien trae profanamente adornado el cuerpo» (Florencia 1955: 269). Paradigma de mujer vanidosa es, para Martínez de la Parra, Sabina Popea, la segunda esposa de Nerón, famosa por poseer una belleza tan grande como su simplicidad, y que bien puede ser reconocida como una sex symbol de la Roma decadente: «Porque Sabina Poppea tenía el cabello como azafrán, de que gustaba mucho Nerón, todas las mujeres de Roma buscaban a todo costo tintas con que teñirse de aquel color los cabellos» (Parra 1701: 24). Pues bien, de ella,

De Sabina Popea, ramera en Roma con nombre de emperatriz, refiere Plinio que, habiendo creído que era a propósito la leche de la burra para alisar y blanquear la tez, a todo costo, embarazo y molestia, a donde quiera que iba, iba cargada de una gran manada de quinientas burras para bañarse siempre en su leche, por conservar

$8 \quad$ Faya 1632: 79r-79v; Mayor 1633: Chorea, 3; Bellarmino 1610: 190; thema: «Les exemples $d u$ Livre des abeilles, Turnhout, 1997, n. ${ }^{\circ} 166$, p. 208»; Tubach 1969: «1429. Dancing, punishment for»; Goldberg 1998: «Q.386.1. Devil punishes young woman who loves to dance»; Thompson 1955-1958: «G303.3.3.1.4. Devil in form of cow (bull, ox)». 
su hermosura: asinarum gregibus ob hoc eam comitantibus. Y qué bien iba entre jumentos quien de ellos mendigaba la hermosura (Parra 1701: 270) ${ }^{9}$.

Como puede verse, la vanidad como tópico descriptivo de la mujer se combina aquí con otro que resulta absolutamente predecible: el tópico de la necedad o estulticia femenina. Se trata de un tópico tan longevo que se puede rastrear en la mayor parte de las literaturas antiguas, lo mismo que en las cristianas; de hecho, la biografía que hizo Laercio de Sócrates fue usada por Martínez de la Parra en el siguiente exemplum, que trata sobre el matrimonio:

Pero, si alguno [de los esposos] ha de ceder, queda la misma duda: ¿quién debe ser? ¡Oh, Dios! Si se conoce la razón, ¿qué hay que preguntar? Y, si no se conoce, ¿qué he de decir? Lo que sé es que Sócrates, digna admiración de Grecia, cedía no pocas veces a una Jantipa, mujer loca y fiera, y que, habiéndole dicho palabras fulminadas de furia, al bajar luego él la escalera, le echó encima un cántaro de agua, y él respondió: «Ya yo sabía que después de los truenos viene el aguacero» (Parra 1701: 446) ${ }^{10}$.

Con este exemplum el predicador ilustra el modo heroico en que los esposos deben ceder a las impertinencias de sus mujeres, ilustración en la que resulta notable y divertida la manera en que el predicador juega con la justificación de haber elegido a Sócrates como ejemplo, pues si Sócrates solo sabía que nada sabía, para el predicador: «lo que sé es que Sócrates, digna admiración de Grecia, cedía no pocas veces $[\ldots] \gg$.

En otro ejemplo del mismo tema, que involucra no solo el buen gobierno de la familia sino el político también (muestra inequívoca del vínculo que existía entre ambas dimensiones de la autoridad), el predicador narra un episodio de la vida de Papirio Pretextato tomado de Macrobio (1986: I, 19-25). Papirio, hijo de un senador romano, se vio obligado a engañar a su madre cuando esta pretendía saber qué se había discutido en el senado una vez que el hijo acompañó allá a su padre, como era la costumbre; el joven, por no divulgar lo que bien sabía era secreto, le dijo a su madre que se discutía el derecho a la poligamia masculina, lo que hizo que la matrona levantara media ciudad en voz de las mujeres para irrumpir en la sesión senatorial del día siguiente con la propuesta de que sería mejor la poligamia femenina. Los senadores, pasada la sorpresa inicial, comenzaron a burlarse, el engaño se descubre y las matronas quedan avergonzadas (Parra 1701: 252) ${ }^{\mathbf{1 1}}$. La intención

\footnotetext{
9 Plinio 1624-1629: XXVIII, 50.

10 Laercio 1566: II, Sócrates 2, 15.

11 Villegas 1652: Discursos 7 y 35; thema: «Alphabet of Tales [ed. Banks, 1904-1905], 141; Jacobus a Vitriaco, Sermones vulgares [ed. Crane, 1890], 235; Le Ménagier de Paris, 16». Tubach 1969:
} 
del ejemplo es censurar el vicio del chisme y la curiosidad desmedida, que en el siglo XVII como en la Antigüedad era atribuido casi de manera natural a las mujeres, y cuyas nefastas consecuencias, como se ve, no solo vendrían a ser domésticas.

La familia gozó de una singular importancia jurídica, económica y política en todos los dominios hispánicos de la época; por ello, los predicadores se ocupaban en persuadir acerca de la norma de conducta que dictaba la mesura en el ejercicio de la autoridad por parte de los pater familias, aunque también (y sobre todo) sobre la debida sumisión por parte de esposa e hijos; en cualquier caso, resulta fácil anticipar que no sería este el comportamiento constante, que pleitos y discusiones aderezarían la vida conyugal, lo que traería al predicador incluso a ofrecer con parábolas remedios a estos males no tan privados. De este modo, en una plática dedicada a tratar «del amor, y respeto, que entre sí se deben los casados», cuenta el ejemplo de una mujer que tenía un marido intolerable: jugador, bebedor y pendenciero, al grado de que «había todas las noches gran pleito, y se alternaban con las voces las manos». La mujer buscó el consejo de un hombre prudente, quien le dio un agua prodigiosa que debía usar de un modo peculiar: debía tomar un trago y tenerlo en la boca desde que llegaba su marido, y mantenerlo en ella mientras le servía, lo que en verdad resultó buen remedio pues cesaron los pleitos y las discusiones, así que cuando el agua se acabó, la mujer tuvo que buscar más en casa del consejero, quien le dice: «Pues mujer [...], sábete que esa agua no es otra que agua de la tinaja; sino que, como teniéndola en la boca te hace callar y tú no le respondes, por eso tu marido se sosiega y calla» (Parra 1701: 197-198). Curioso remedio que no condena los vicios del marido sino solo la insumisión de la esposa.

Por eso, por necia, vanidosa, avara y lujuriosa, la mujer debía sujetarse, debía someterse a la autoridad jurídica, moral, política y física de su marido; subordinación necesaria para conservar el orden adecuado en los asuntos públicos y privados y, a la postre, para la propia salvación del alma. Así, para ilustrar un camino de solución a los pleitos conyugales, el jesuita Martínez de la Parra acude a una fábula muy bella tomada de los Moralia de Plutarco, que inicia: «Apostaron una vez el viento y el sol a cuál más mañoso salteador le quitaba de los hombros la capa a un pobre caminante, que por lo descubierto de un llano iba expuesto a sus inclemencias»; el viento desató entonces todas sus furias y soltó sus huracanes, no logrando sino que el caminante más se aferrara a su capa, de modo que «ni bastando porfías ni violencias, después de gran batalla dejó burlado al viento con sus furias»; en cambio,

«5269. Wife and secret senate. A son earns the senate's respect when he tells his mother, who is overly curious about the proceedings of the secret senate, that the members were deliberating about whether or not a man should be allowed two wives»; Goldberg 1998: «X35. Son lies to mother, inventing wild tales about secret senate debate: men to have two wives; women to have two husbands. She divulges secret to others, and they confront senate. Woman made to look foolish». 
el sol se limitó a calentar poco a poco, sin violencias, «creciendo sus bochornos, mudo combatiente pero eficaz, sosegado pero más poderoso, sin ruido pero más activo», de modo que muy pronto el caminante no solo se quitó la capa, sino aún se aflojó la ropa por ver si así aminoraba el calor. A lo que el predicador concluye:

¿Qué? ¿No está en lo furioso, no en lo violento la fuerza que llega hasta quitarle a un hombre la capa? No. ¿Pues a quién digo yo esto? ¿A un marido que en lo rústico del genio pone en violentas furias su mando? ¿O a una mujer que en lo terco de un natural voluntarioso piensa con necias porfías atropellar lo justo de su sujeción? A uno y a otro se lo dice con bien moral enseñanza Plutarco, sea la mujer o sea el marido (Parra 1701: 444) ${ }^{12}$.

Por supuesto, antes que la belleza y la poesía de esta fábula cae ante nuestros ojos «lo justo» que la sujeción femenina parece a los ojos de un predicador del siglo XVII novohispano y a los ojos (oídos) de su auditorio. Ya Michel Foucault denunciaba el control de la mujer como condición sine qua non de sobrevivencia del modelo social; en su Historia de la sexualidad trata sobre la necesidad moderna de controlar sus cuerpos, física y funcionalmente: sumisión femenina al hogar y a la reproducción (Foucault 2003: 99-125).

Recuérdese que el exemplum en principio entraña una analogía, pues obtiene su carácter probatorio o ilustrativo de una causa expositiva a partir de la comparación de la misma con un asunto externo, aunque similar a dicha causa. Esta función ilustrativa por comparación concentra y potencia las posibilidades didácticas del relato ejemplar al plantear una enseñanza con base en un paradigma moral, en el que es posible observar la propuesta paradigmática de uno o varios modelos de virtud a seguir, o bien encontrar el castigo derivado de quebrantar las leyes religiosas, naturales o civiles. Quintiliano había establecido los tres modos en que la comparación ejemplar podía tener lugar en el discurso: en su relación de «semejanza» con la causa, en relación de «desemejanza» o el «ejemplo contrario» (exemplum ex contrariis); los ejemplos «semejantes» a la causa son aquellos que la ilustran de manera directa, como traer un fragmento de la vida de san Francisco de Asís para dibujar la perfecta virtud de la pobreza; una comparación «desemejante» sería aquella que aclara un hecho similar al propuesto en la causa pero realizado por razones distintas, como proponer los trabajos de Hércules como ejemplo de fortaleza cristiana; mientras que el exemplum ex contrariis explica la

12 Plutarco 1986: t. II, 183; thema: «Ci nous dit, 347, 1-4; Dicke-Grubmüller, Die Fabeln des Mittelalters... [München, 1987], n. ${ }^{\circ}$ 532, pp. 610-613; proverbe: On obtient plus par douceur que par violence, par astuce que par force, par amitié que par contrainte. Cf. Morawski, Les proverbes français [...], $\mathrm{n} .^{\circ} 1287 »$. 
acción opuesta a la que se pretende enseñar, es decir, una suerte de «contraejemplo» que incluye el castigo para el infractor (Quintiliano 1996: V, XI, 5).

Estos tres modos de comparar suponen también diferencias en cuanto al objetivo didáctico con que se insertaban los ejemplos: en primer lugar, el reforzamiento de un comportamiento virtuoso mediante los ejemplos semejantes y desemejantes, considerando diferencias en cuanto al grado de prueba entre unos y otros; en segundo, el castigo de un vicio o bien la propuesta de una vía al arrepentimiento y la rectificación mediante los ejemplos contrarios. Desde esta perspectiva es posible observar las representaciones femeninas presentes en nuestros exempla novohispanos, y lo primero que encontraremos es que la mayor parte de los estudios al respecto han insistido sobre todo en las formas de ejemplaridad contraria, que proponen modelos negativos de mujeres a la sombra de la misoginia cultural; del mismo modo, encontraremos que se han dejado un poco de lado en estos estudios las formas de ejemplaridad «semejante» que ilustrarían un modelo teórico de mujer, mostrando ya no sus vicios sino sus virtudes deseables en un marco de utilidad social.

Porque en los discursos religiosos no solo se reutiliza el tópico de la mujer viciosa, sino también el modelo idealizado de lo femenino heredado del amor cortés, así como el modelo santificado de la Virgen; es decir, el modelo de representación religiosa de lo femenino no se agotaba en la estigmatización de las mujeres, sino que podía incluir también su idealización utilitaria. Por ello, no parece del todo correcto tratar de la mujer como entidad monolítica o singular en los textos religiosos pues, como afirma Riley, la mujer, además de un sujeto social es una categoría histórica cuya realización resulta de una relación dialéctica entre el ideal impuesto y sus circunstancias sociales y económicas (Riley 1988: 9-43). Para la observación de esta otra ejemplaridad debe tenerse en cuenta también la noción de estamento, a fin de comprender que, a pesar de los comunes denominadores de la representación femenina, hay singularidades propias de la raza o el grupo social, que significaban diferencias importantes en cuanto a control social y utilidad económica de las diferentes clases de sujetos femeninos.

A la mujer de élite se la hizo encarnación del ideal femenino, de modo que también sufrió una gran presión social para ajustarse al modelo construido y sostenido desde los púlpitos (Gallardo 2011: 108). Este ideal femenino se nutría de valores asociados a la dócil sujeción, la conservación de la honra familiar, la correcta observancia de la religión, la práctica de la misericordia, la buena crianza de los hijos y, en general, la buena administración del hogar, para lo que debería recibir cierta formación emocional e intelectual, aunque siempre limitada a este fin utilitario ${ }^{13}$; ello trajo a moralistas y predicadores a enfrentar la contradicción

13 Pues a la mujer se le concedió, como afirma Craveri, «una importante misión espiritual en el seno de la sociedad civil, dándose prisa por instruirla» (Craveri 2014: 139; véase también Gonzalbo 
de instruir a la mujer sin que por ello se la exponga a la influencia perniciosa de la razón y la libertad, esencia de todo saber. El humanista Juan Luis Vives, por ejemplo, confrontó la misoginia corriente de la predicación: «Salpicáronse copiosamente de ridículo aquellos moralizadores [...] que atacaron con ciego arrebato al sexo todo, pero no se desataron en idéntico furor contra el sexo masculino» (Vives 1947: 1.309), aunque sin dejar de atribuir a la mujer fragilidad física y moral como nota característica (Martí 2004: 375).

¿Qué molestia la de todos los meses cuando se purga aquella especie de sentina que es el útero! ${ }^{14}$ ¡Qué ascos les ocasiona el preñado! ¡Qué peligros los del parto los del puerperio, de los cuales salen quebrantadas! [...] Y todo el restante discurso de su vida. ¿Qué es sino un continuo servicio del hombre? De doncellas sirven a sus padres; de casadas sirven al marido; de madres sirven a sus hijos. Y puesto que tienen menos reciedumbre y fuerza en su alma, su juicio es más débil y su instrucción más limitada y están menos enseñadas por la práctica y por la experiencia (Vives 1947: 1340$)^{15}$.

En cualquier caso, se trata de una función social a cuyo establecimiento pudo haber ayudado el fortalecimiento de la dimensión política que tomaba la virtud cristiana en esos años (y por lo menos desde el siglo XVI), como deja muy en claro el obispo Juan de Palafox:

El vicio en las monarquías no sólo destruye lo espiritual y moral, sino lo político, porque al tiempo que quita a las almas la gracia y a los reinos la protección de Dios, enflaquece el valor y constancia de la nación, y se pierde con eso el consejo y la opinión; y luego comienzan a servir con los vicios los que mandan a otros con las virtudes (Palafox 1994: 5) ${ }^{16}$.

Por ello se sucedían encomios y exhortos a la virtud femenina, inspirados no solo en la tradición hagiográfica, sino incluso en la antigüedad grecolatina, como hace el cronista carmelita fray Agustín de la Madre de Dios:

1998: 5). Porque en el nuevo régimen, monárquico y centralista, la mujer sirvió para afianzar las antiguas costumbres: «La Introduction à la vie dévote de San Francisco de Sales, escrita a principios del siglo XVII para una mujer de la alta nobleza llamada a mantener su rango en la sociedad, ya se proponía ir más lejos y hacer de la cortesía un arte cristiano» (Craveri 2014: 135).

14 Como enfermedad paradigmáticamente femenina, recuérdese que la palabra «histeria» viene del griego hýsteron, que significa precisamente «útero».

15 La Instrucción de la mujer cristiana, de Juan Luis Vives, fue quizás el tratado fundamental para guiar la educación femenina en la época.

16 Por lo demás, son ya bastante conocidas las opiniones de Palafox sobre las mujeres, su proverbial misoginia. Un buen y reciente artículo al respecto es el de Saranyana (2010: 291-304). 
A Claudia, virgen vestal, refiere Valerio Máximo la recibió Roma en triunfo al lado de su padre, porque si éste venció con armas los enemigos, ella se venció a sí misma con el trofeo de la castidad. A Fatua, virgen romana, la dedicaron templo y levantaron estatua en aquella gran república aclamando según Pomponio Leto su honestidad excelente, no sólo historiadores sino también patricios; no solamente hombres sino también mujeres con el nombre y apellido de la buena diosa, porque resistió valiente al deseo de su padre que ardía incestuoso en llamas de lujuria y sufrió de él palabras afrentosas y castigos con varas de arrayán. A la hija de Petérculo, Sulpicia, celebró la antigüedad (según Volaterrano) con aras, con estatuas y con templo porque la vieron honesta y afecta a la pureza virginal; en cuyo templo no entraban si no es los llamados Salios que eran del orden patricio, como fueron Apio Claudio, Scipión Africano, Lucio Bíbulo, que todos habían sido triunfadores de bárbaros enemigos, queriendo aquella república que sólo celebrasen las proezas de quien triunfó del vicio deshonesto, los que supieron triunfar de fuertes enemigos. Pues si estos sucedió entre los gentiles que tan poco apreciaban la honestidad virginal, ¿qué fuera justo hicieran los cristianos con quien tantas victorias consiguió de todos los poderes del infierno? (Madre de Dios 1986: IV, 16, 3).

En el siglo XVII las mujeres novohispanas de la clase dominante cumplían funciones de estabilidad ideológica y doctrinal, marcaban las reglas de etiqueta y dictaban el estilo de vida señorial, encontrando incluso en el monopolio del decoro un arma defensiva capaz de suavizar su inferioridad jurídica. Algunos llegan a decir en este sentido, sin duda exagerando, que el sometimiento de la mujer a los varones no era ya tanto en el XVII como en los siglos anteriores; que, en comparación con el sometimiento de los hijos a sus padres:

la situación de las mujeres era bastante diferente, pese a la tan reiterada minoría de edad permanente en la que se supone que estaban sumidas. Con acceso al trabajo y a la propiedad, y responsables de sus decisiones a la hora de tomar estado, las mujeres novohispanas tuvieron influencia en varios terrenos, pero, muy especialmente, en el ámbito doméstico (Gonzalbo 1998: 2).

No estoy tan seguro; en cualquier caso, si el control moral y el decoro familiar eran importantes funciones sociales que en efecto recaían en las mujeres, «las salidas descontroladas de las damas o la infidelidad de la esposa se consideraban como dos de los más graves pecados femeninos ya que comprometían la sucesión del linaje familiar» (Baena 2011: 98); lo cual, en lugar de significar espacios de libertad para la mujer, justificaba el encierro, la saturación de tareas domésticas $\mathrm{y}$, por supuesto, una dura educación que excluía por sistema la enseñanza de las artes humanísticas.

Además, a pesar de la importancia de las funciones cumplidas al servicio de la estabilidad social, tampoco las mujeres novohispanas de la élite escaparon a una 
denigrante inferioridad jurídica; inferioridad relacionada con aquella consideración de los débiles como personas miserables que presentaba la doctrina romana del Bajo Imperio en la figura del Defensor civitatis (Cuena 1998) ${ }^{17}$; y de ello también daban cuenta estas representaciones femeninas: recuérdese que el discurso judicial y el deliberativo, la práctica penal y el púlpito, estaban profundamente imbricados en el siglo XviI, porque la norma no podía concebirse de otro modo que en una relación dialéctica con la costumbre, a la que intentaba sujetar, a veces de modo profiláctico desde los púlpitos. El vínculo entre discurso religioso y judicial es tan amplio y profundo que en no pocas ocasiones confundieron sus objetivos, como queda claro en esta terrible afirmación de Martínez de la Parra en una plática destinada a disuadir contra el robo: «Y para predicarlo mudo, mejor le sirve de púlpito a un verdugo la horca» (Parra 1701: 225).

Así, aunque se encomiasen sus virtudes, las mujeres novohispanas de la élite seguían viviendo en una inferioridad jurídica e ideológica determinante; de modo que si hubo diferentes clases de mujeres en el México colonial hubo también diferentes representaciones de lo femenino: la mujer española y rica, la mestiza, la india o la negra; aunque cada grupo étnico, cada grupo socio-económico de mujeres realizó su inferioridad y sujeción de modos distintos y con distintos grados de participación en la cultura masculina. Se trata en última instancia de la actualización de la vieja misoginia medieval que no cambió ni siquiera con los nuevos aires del Humanismo renacentista; por el contrario, no falta quien argumente, incluso, que en esos luminosos tiempos hubo lugar para una regresión de la condición femenina, desde que la vuelta a los valores del mundo grecolatino renovó el prestigio del derecho romano, claramente desfavorable a las mujeres (Craveri 2014: 131); en el siglo XVI el jurista Jean Bodin, teórico del Estado absoluto, mostraba ecos de la norma romana al considerar «que éstas [las mujeres] debían ser apartadas de todos los lugares de mando y de decisión, de las asambleas públicas y de los consejos y que únicamente debían ocuparse de los asuntos propios de su sexo» (Bodin 1586: 365).

A final de cuenta no hay contradicción en esta doble ejemplaridad femenina; porque desde la ideología religiosa, incluso la científica de la época, la mujer es un animal instintivo y, por tanto, se le debe domar con castigos o con regalos, se le debe tratar como áspid peligrosa si no ha tenido el refinamiento de la cultura y, si lo ha tenido, entonces debe tratársele como un relicario de virtudes inverosímiles: en cualquier caso, se le ha de mantener siempre lejos del poder y de la justicia, y

17 Aunque con mayor seguridad lo encontraríamos en el Ius commune medieval. La palabra miserabilis aparece por primera vez en contexto jurídico en la constitución de Constantino, obligando a la intervención del emperador para proteger a los débiles (huérfanos, viudas, etc.); etimológicamente, miserable es toda persona necesitada de misericordia o conmiseración y, de modo técnico y para efectos judiciales, miserable es toda persona incapaz de valerse por sí misma. 
siempre subordinada. Una lectura de un abanico de posibilidades de representación femenina ha sido posible aquí gracias al reconocimiento de que la ejemplaridad de los textos estudiados no siempre se resuelve de modo contrario, trayendo al discurso el paradigma femenino del vicio, sino también por un camino recto, mediante la representación de las virtudes que se han de persuadir; lamentablemente, los espacios para la virtud femenina que ofrecen los ejemplos semejantes del siglo XVII siguen siendo asfixiantes, hijos de una ideología patriarcal de largo aliento que debería esperar todavía siglos para comenzar a desaparecer.

\section{BibLIOGRAFÍA}

Baena Zapatero, Alberto (2011). «Las mujeres españolas y el discurso moralista en Nueva España (s. XVI-XVII)». En Jaime Contreras y Raquel Sánchez (coords.), Familias, poderes, instituciones y conflictos. Murcia: Universidad de Murcia, pp. 93-106.

Bavel, Tarcisio J. van (1994). «La mujer en san Agustín». Estudio Agustiniano, 29, pp. 3-49.

Bellarmino, Roberto (1610). Declaración copiosa de la doctrina Christiana: para instruir los idiotas, y niños en las cosas de nuestra santa fe cathólica. L. de Vera (trad.). Barcelona: Imprenta de Gabriel Graells y Gerardo Dotil.

Bodin, Jean (1586). De Republica libri sex. Paris: Jacobo du Puys.

Bоотн, Wayne C. (1983). The Rhetoric of Fiction. Chicago: The University of Chicago Press.

Cangas Arreola, Omar Daniel (2006). «El amor se volvió mujer. Las mujeres y el amor en el México colonial». Avances, 132, pp. 1-28.

Castillo Hernández, Estela (2014). «Del sermón y sus excesos: aversión a las mujeres en la Nueva España del siglo XVIII». Dieciocho, 37, pp. 33-62.

CÁtedra García, Pedro (1986). «La mujer en el sermón medieval (a través de textos españoles)». En Yves-René Fonquerne (ed.), La condición de la mujer en la Edad Media. Madrid: Universidad Complutense de Madrid, pp. 39-50.

CHARTIER, Roger (1992). El mundo como representación. Historia cultural: entre práctica y representación. Claudia Ferrari (trad.). Barcelona: Gedisa.

Coe, Sophie D. y Michael Coe (1996). The True History of Chocolate. London: Thames and Hudson, Ltd.

Craveri, Benedetta (2014). «La contribución de las mujeres a una nueva forma de civilidad (ss. XVII-XVIII)». En Mónica Bolufer, Carolina Blutrach y Juan Gomis (eds.), Educar los sentimientos, una mirada desde la historia. Zaragoza: Institución Fernando «el Católico».

Cuena Boy, Francisco (1998). «El Defensor Civitatis y el Protector de Indios: breve ilustración en paralelo». Ius Fugit, 7, pp. 179-195.

FAYA, Alejandro (1632). Summa de exemplos de virtudes, y vicios. Sevilla: Francisco de Lyra. 
Florencia, Francisco de (1955). Historia de la provincia de la Compañía de Jesús de Nueva España. Ciudad de México: Academia Literaria.

Foucault, Michel (2003). Historia de la sexualidad. 3. La inquietud de sí. Tomás Segovia (trad.). Buenos Aires: Siglo XXI.

Gallardo Arias, Patricia (2011). «La transgresión al ideal femenino cristiano y una acusación por brujería en Valle del Maíz». Estudios de Historia Novohispana, 44, pp. 77-111.

Goldberg, Harriet (1998). Motif-index of Medieval Spanish Folk Narratives. Tempe: Arizona State University.

Gonzalbo Aispuro, Pilar (1998). «Con amor y reverencia. Mujeres y familias en el México colonial». Jahrbuch für Geschichte Lateinamerikas. Anuario de Historia de América Latina, 35-1, pp. 1-24.

Laercio, Diógenes (1566). De vita et moribus philosophorum libri X. Lugduni: Antonio Gryphio.

LEÓN, fray Luis de (1972). La perfecta casada. Genève: Femi.

López Beltrán, Clara (2005). «Espiritualidad y moral en la cultura femenina. Charcas, siglo XVII». En S. O’Phelam Godoy y C. Salazar-Soler (eds.), Passeurs, mediadores culturales y agentes de la primera globalización en el Mundo Ibérico. Siglos XVI-XIX. Lima: IFEA, pp. 283-293.

MAdre de Dios, Agustín de la (1986). Tesoro escondido en el monte Carmelo mexicano. Mina rica de exemplos y virtudes en la historia de los Carmelitas descalzos de la Provincia de la Nueva España. Eduardo Báez (ed.). Ciudad de México: Universidad Nacional Autónoma de México.

MARTí, Sacramento (2004). «El oficio de mujer en las obras de Juan Luis Vives y fray Luis de León». En Isaías Lerner, Roberto Nivel y Alejandro Alonso (eds.), Actas del XIV Congreso de la AIH. Newark: Juan de la Cuesta, II, pp. 375-381.

MARTíneZ de la PARRA, Juan (1701). Luz de verdades cathólicas, y explicación de la doctrina cristiana, que siguiendo la costumbre de la casa professa de la Compañia de Jesus de México, todos los jueves del año ha explicado en su iglesia el padre Juan Martinez de la Parra, professo de la misma Compañia. Barcelona: Juan Jolis.

MAYOR, Juan (1633). Magnum speculum exemplorum. Douai: Baltazaris Belleri.

MÉndez, María Águeda (2001). Secretos del oficio. Avatares de la Inquisición novohispana. Ciudad de México: El Colegio de México.

Olmos, Andrés de (1990). Tratado de hechicería y sortilegios. Ciudad de México: Universidad Nacional Autónoma de México.

Ortega, Sergio (1987). El discurso teológico de Santo Tomás de Aquino sobre el matrimonio, la familia y los comportamientos sexuales. Ciudad de México: Universidad Nacional Autónoma de México.

Palafox y Mendoza, Juan de (1994). Ideas Políticas. Ciudad de México: Universidad Nacional Autónoma de México.

PÉrez, Manuel (2008). Historias y cuentos para la reforma de costumbres en Nueva España: Retórica del ejemplo en Luz de verdades católicas (1692-1699) de Juan Mar- 
tínez de la Parra, S. J. Aurelio González (dir.) [tesis doctoral]. Ciudad de México: El Colegio de México.

PÉREZ, Manuel (2011). Los cuentos del predicador. Historias y ficciones para la reforma de costumbres en la Nueva España. Madrid/Frankfurt am Main: Iberoamericana/ Vervuert.

PÉREZ, Manuel (2012). Los cuentos del historiador. Literatura y ejemplo en una historia religiosa novohispana. Madrid/Frankfurt am Main: Iberoamericana/Vervuert.

PÉREZ, Manuel (2017). Retórica del exemplum en discursos religiosos novohispanos del siglo XVII. María Jesús Lacarra (dir.) [tesis doctoral]. Zaragoza: Universidad de Zaragoza.

PÉREZ, Manuel (2018). Exempla novohispanos del siglo XVII. Madrid/Frankfurt am Main: Iberoamericana/Vervuert.

Plinio Segundo, Cayo (1624-1629). Historia natural. Gerónimo de la Huerta (trad.). Madrid: Juan González.

Plutarco (1986). Moralia. Concepción Morales Otal y José García López (trads.). Madrid: Gredos.

Quintiliano, Marco Fabio (1996). De Institutio Oratoria. Alfonso Ortega Carmona (trad.). Salamanca: Publicaciones Universidad Pontificia.

Ranke-Heinemann, Uta (1994). Eunuco por el reino de los cielos. Iglesia católica y sexualidad. Víctor A. Martínez (trad.). Madrid: Trotta.

RILEY, Denise (1988). Am I That Name? Feminism and the Category of Women in History. Minneapolis: University of Minnesota.

Río, Martín del (1608). Disquisitionum magicarum libri sex. Lugduni: Horatio Cardon.

Saranyana, Josep-Ignasi (2010). «Cómo vio Palafox a las mujeres». En Ricardo Fernández Gracia (ed.), Varia palafoxiana. Doce estudios en torno a don Juan de Palafox y Mendoza. Pamplona: Gobierno de Navarra.

Thesaurus exemplorum Medii Aevi [ThEMA] <http://gahom.ehess.fr/index.php?434>.

Thомpson, Stith (1955-1958). Motif-index of Folk-literature: A Classification of Narrative Elements in Folktales, Ballads, Myths, Fables, Mediaeval Romances, Exempla, Fabliaux, Jest-books, and Local Legends. Bloomington: Indiana University Press.

Tubach, Frederick C. (1969). Index Exemplorum. A Handbook of Medieval Religious Tales. Helsinki: Akademia Scientiarum Fennica.

Uther, Haus-Jörs (2011). The Types of International Folktales. A Classification and Bibliography. Helsinki: Akademia Scientiarum Fennica.

VILlegas, Alonso de (1652). Flos sanctorum. Madrid: Melchor Sánchez.

VIVES, Juan Luis (1947). De oficio mariti. Madrid: Aguilar.

Recibido: 22/07/2019

Aceptado: 30/08/2019 


\section{雾}

DOBLE EJEMPLARIDAD DE LA MUJER EN DISCURSOS RELIGIOSOS NOVOHISPANOS DEL SIGLO XVII

RESUMEN: La presencia de la mujer en discursos religiosos es asunto bien estudiado, aunque se ha insistido más en los poderosos tópicos misóginos que guían su representación, y menos en sus valoraciones positivas. En este artículo se exponen los resultados de un breve estudio retórico de las representaciones femeninas en discursos religiosos novohispanos, a partir de uno de los lugares del discurso donde es posible observar con mayor claridad su dimensión ideológica: la argumentatio, el lugar de las pruebas. Quintiliano había establecido tres modos en que la comparación ejemplar podía tener lugar en el discurso: en su relación de «semejanza» con la causa, en relación de «desemejanza» o el «ejemplo contrario»; la mayor parte de los tópicos misóginos religiosos - cuya observación ha sido dominante en los estudios al respecto- corresponden técnicamente a usos ejemplares contrarios a su causa, pero la representación femenina no se agota en estos tópicos pues falta una serie importante de representaciones semejantes, que muestran ya no los vicios de las mujeres sino sus virtudes deseables y su utilidad social. En cualquier caso, los espacios para la virtud femenina que encontramos en los ejemplos semejantes siguen siendo asfixiantes e injustos para las mujeres; aunque su observación permite completar el marco de posibilidades de representación femenina en discursos religiosos, y permite además determinar otro modo de realización retórica de dichas representaciones.

PALABRAS ClaVE: mujer, exemplum, retórica religiosa, Nueva España.

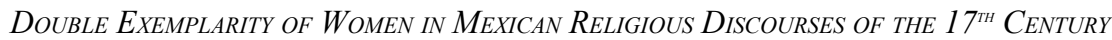

ABSTRACT: The presence of women in religious discourses is a well-studied issue, although more important emphasis has been placed on the powerful misogynistic topics that guide their representation, and less on their positive assessments. This article presents the results of a brief rhetorical study of female representations in Mexican Colonial religious discourses, from one of the places of discourse where it is possible to observe more clearly its ideological dimension: the argumentatio, the place of proofs. Quintiliano had established three ways in which the exemplary comparison could take place in the discourse: in relation of similarity to the cause, in relation of dissimilarity, or the opposite example; most of the religious misogynistic topics — whose observation has been dominant in the studies in this regard - correspond technically to exemplary uses contrary to their cause, but this does not includes all the possibilities of female representation because there is a lack of important series of representations used as straight or similar examples, which no longer show the vices of women but their desirable virtues and social utility. In any case, the spaces for feminine virtue that we find in similar examples remain asphyxiating and unfair to women, although its observation allows to complete the framework of possibilities of female representation in religious discourses, and also allows to determine another way of rhetorical realization of these representations.

KEYWORDS: woman, exemplum, religious rhetoric, New Spain. 